\title{
Visual illusions in the baboon (Papio anubis)
}

\author{
EFRAIM BENHAR and DAVID SAMUEL \\ Brain and Behaviour Group, Department of Isotope Research, Weizmann Institute of Science \\ Rehovot, Israel
}

\begin{abstract}
Two baboons were trained on oddity problems with sets of stimuli involving parallel lines. When stable discrimination performance had been established, occasional test trials were run with Zollner illusion figures. Both animals appeared to have been deceived by the illusion.
\end{abstract}

Visual illusions in people have attracted the attention of physicists, psychologists, and physiologists for many years (Robinson, 1972; Tolansky, 1964). For over a hundred years, a range of different types of illusions have been investigated, particularly the Müller-Lyer, the Zöllner, the Poggendorf, and the Ponzo illusions, among many others (Ward, Porac, Coren, \& Girgus, 1977).

There have been suggestions that the perception of such geometrical illusions is due to the deliberate modification of certain perceptual features in the environment with the increasing experience of the observer (Gregory, 1963, 1966). This suggestion has not been supported by experiments. For example, students were tested for the role of primary depth cues in which the Ponzo illusion was incorporated into two pictures depicting concrete scenes. The standard abstract illusion remained unaltered when the Ponzo figure in the picture represented the vertical face of an object, but the sense of illusion was increased when the figure represented an object extending in depth, which was interpreted as failure to support Gregory's suggestion (Newman \& Newman, 1974). In another experiment (Worall, 1974), in which the converging lines of primary depth were suggested independently of the Ponzo illusion, no support was found for a theory based on the experience of the observer.

Since animals lack most, if not all, of the cultural background of human beings and live in an entirely different natural environment, they could be useful subjects for ascertaining the degree to which the environment in which they were raised influences their susceptibility to visual geometrical illusions (Ernst \& Dericco, 1976). A number of animal species have been tested for this susceptibility. Dücker (1966) has compiled a bibliography of experiments on the effect of visual illusions in fish, birds, and guinea pigs. In fish, for example, Herter (1930) found that Phoxinus laevis $\mathrm{L}$. are deceived by the Müller-Lyer and other visual illusions. The nonhuman primate has a brain and a visual system similar to those of humans with

The technical assistance of Itzhak Sher is appreciated. respect to color vision (De Valois, 1968) and to stereoptic precision (Sarmiento, 1975; Young \& Farrer, 1970).

The only published report of a study on visual illusion in monkeys was published 27 years ago (Dominguez, 1954). That author attempted to study in five monkeys from different species (Macaca mulatta, Cercocebus fuliginosa, and Cebus capucina): (1) an illusion of breadth of rectangles, (2) a verticalhorizontal illusion using areas, and (3) a verticalhorizontal illusion using lines. After a long training period, these monkeys were found to be susceptible to these types of geometrical illusions. Dominguez's experiments used paradigms not usually employed in studies of visual illusions in people. We decided to investigate whether a highly developed monkey, such as the baboon, is deceived by the better known Zollner illusion, in which parallel lines appear nonparallel due to oblique transverse lines (Figure 1).

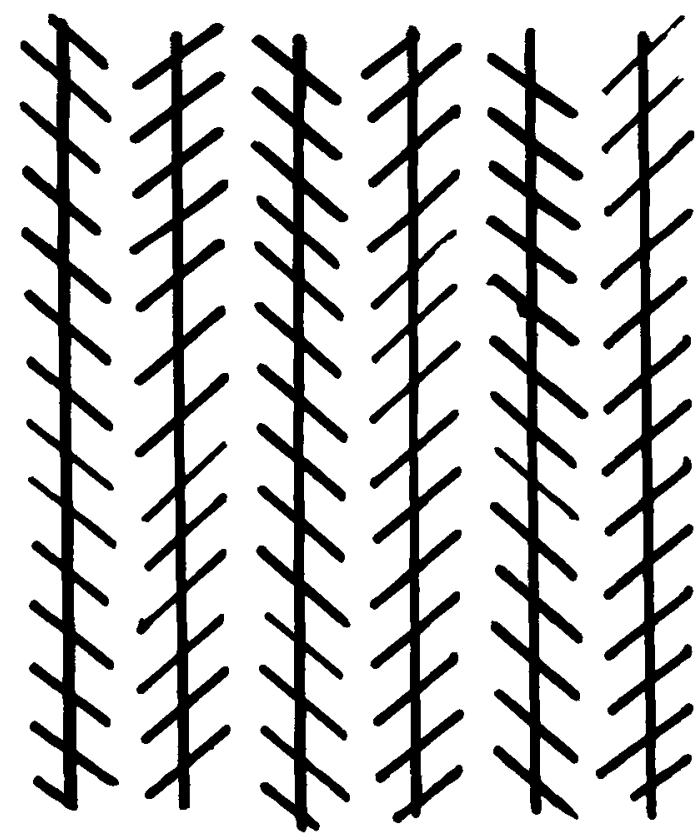

Figure 1. Zölner illusion. The vertical lines are, in fact, parallel. The illusion is due to the short transverse lines. 
This investigation is the first step in a study of the effect of rearing and of the environment on visual perception.

\section{MATERIALS AND METHODS}

Two feral, 6-year-old, male olive baboons (Papio anubis), Shovav and Tintan, were used in this experiment. ${ }^{1}$ The animals had been kept singly in cages in our baboon colony for 5 years (Benhar \& Samuel, 1973) and had previously been used in various tests of discrimination of shape and color (Benhar \& Samuel, Note 1), in experiments on self-recognition in a mirror (Benhar, Carlton, \& Samuel, 1975) and on the use of tools (Benhar \& Samuel, 1978).

For this experiment, a collection of white cards, $75 \times 100 \mathrm{~mm}$, was prepared for use in a Wisconsin General Test Apparatus (WGTA) that was fitted with a tray for accommodating three cards (Figure 2). The cards depicted different patterns with either parallel or nonparallel vertical lines, some with oblique cross-hatchings and others with heavy lines.

During the training phase, various triads of cards were presented in all the 36 possible combinations, thereby ensuring that in each presentation two cards had a parallel pattern and the third had a nonparallel pattern, or vice versa. The animals were trained in an oddity task. In this task, any one of the cards in a triad could be the odd card in one triad and also one of an identical pair in another triad. A choice of the odd card in a triad was always rewarded. This form of the oddity paradigm prevented the monkey from trying to remember which card was "correct".

During the first stage of the experiment, the behavior of each monkey was shaped, using three groups of cards. In Group 1, the odd card was conspicuously distinguishable (Figure 3). In Group 2, of intermediate difficulty (Figure 4), the odd card looked somewhat similar to the other two. Group 3, the most difficult, consisted of triads that contained each two odd-card combinations, but the correct choice was a card on which only the vertical lines differed from those on the two other cards (Figure 5). Eventually, three to four different combinations of cards were presented in a single session, the odd card being placed according to a random sequence based on one suggested by Fellows (1967).

Each monkey had a daily session of 24 trials, 6 days a week, using the noncorrection method until it reached a criterion of $80 \%$ or more correct choices. In the following daily sessions, a test card with the Zollner illusion (Figure 6) was included in the triad. Every test triad contained one card with nonparallel lines and another with parallel lines. If the monkey was deceived by the illusion, the odd card would have parallel lines; if he was not deceived, the correct choice would be one with nonparallel lines. In both cases, the monkey had to refrain from choosing the Zölner illusion test card. The possibility existed that each monkey might eventually learn not to choose this card. Therefore, after each monkey was deceived in three sessions, the Zollner test card (i.e., the "correct" choice) was presented from time to time together with two parallel patterns.

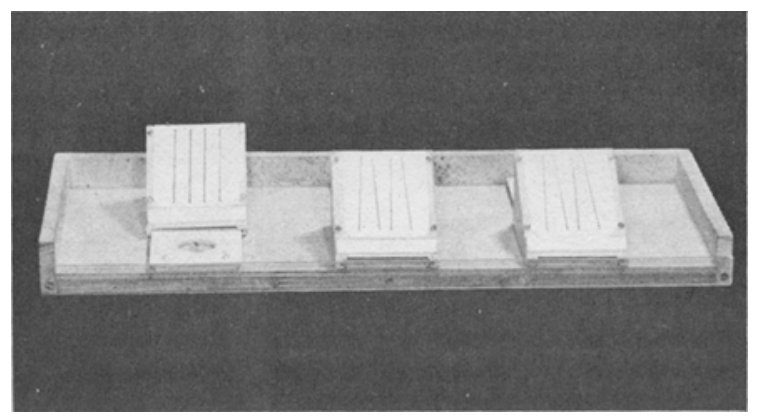

Figure 2. Tray to accommodate cards in various pattern discrimination tasks in a WGTA.
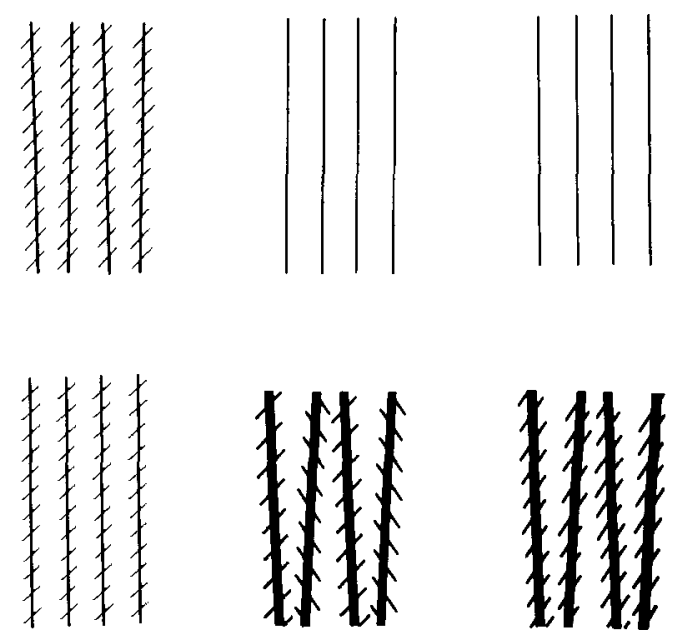

Figure 3. Example of triads of Group 1 (see text). The odd cards on the left are easily distinguishable.
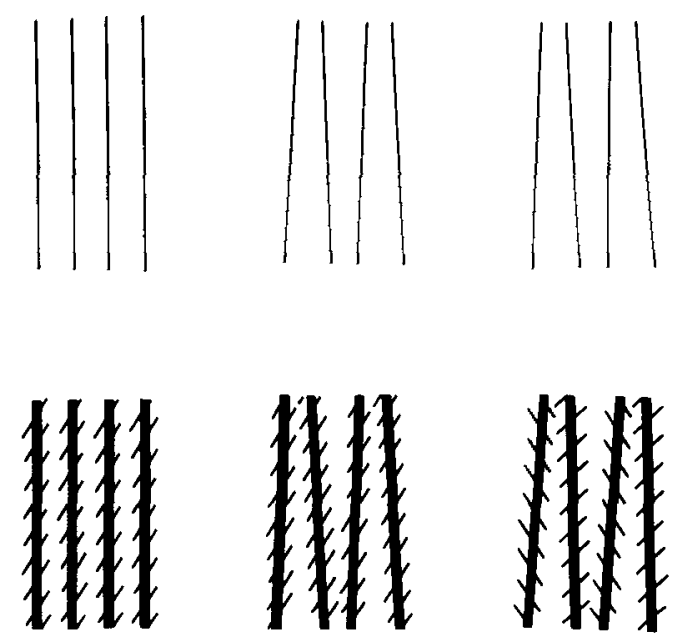

Figure 4. Example of triads of Group 2 (see text). The odd cards are on the left.
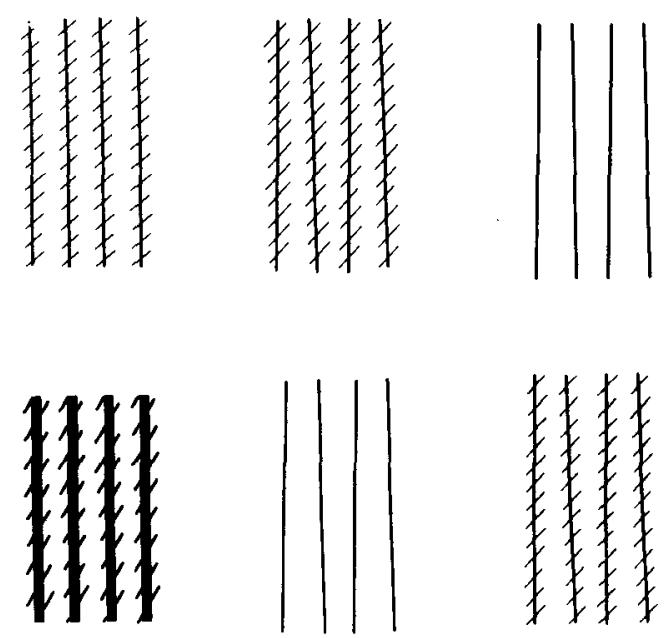

Figure 5. Example of triad of Group 3 (see text). The odd cards are on the left. In the upper row, the right pattern is also odd, but subjects learned to compare only the vertical lines. 

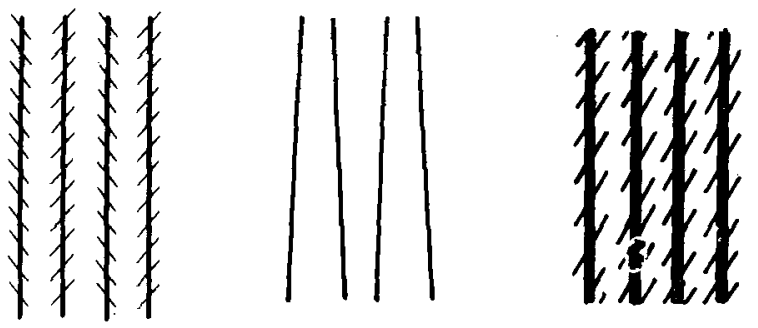

Figure 6. Example of test triad. The card with the Zölner illusion is on the left.

\section{RESULTS}

Both baboons were deceived by the illusion. Shovav reached the first $80 \%$ correct criterion after 1,128 trials. His general performance (Figure 7) shows a series of typical learning curves, each being related to a different set of the three groups of cards of increasing difficulty. He was confronted 33 times with the test card and on only three occasions made a response inconsistent with being deceived by the illusion. Tintan initially had difficulties in learning the oddity problem. He was therefore trained on a simpler discrimination task using the same cards. He reached a criterion of $80 \%$ correct choices on 360 trials. On the subsequent 864 trials, he was confronted five times with the test card and in each case was deceived by the illusion. He was then trained on the oddity test with three cards and reached a criterion of $80 \%$ cor-

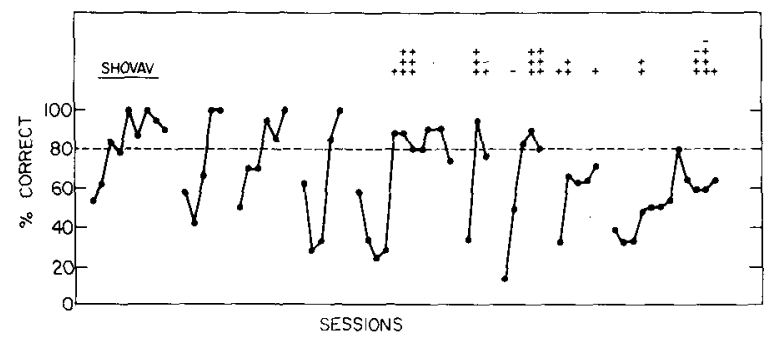

Figure 7. Learning curve and results of tests for Shovav. Each point is the result of a single session. A plus $(+)$ sign indicates a correct choice when confronted with the Zöliner card. A minus $(-)$ sign indicates an incorrect choice.

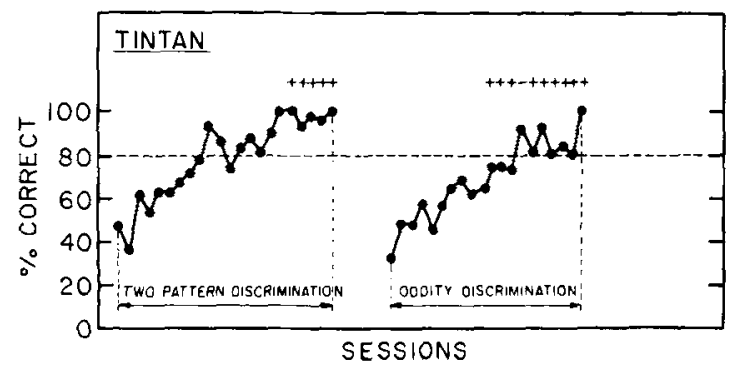

Figure 8. Learning curve and results of tests for Tintan. Each point is the mean of four sessions. A plus ( + ) sign indicates a correct choice when confronted with the card with the Zölner illusion. A minus ( - ) sign indicates an incorrect choice. rect after 1,025 trials. During the subsequent 600 trials, the test Zöllner illusion card was presented 10 times and on 9 occasions he was deceived (Figure 8).

\section{DISCUSSION}

It is not easy for a baboon to discriminate between cards with parallel or nonparallel lines and to disregard every other component of a pattern. This may, in part, be due to the fact that monkeys have greater difficulty in discriminating between two-dimensional drawings or patterns than between three-dimensional objects (Meyer, Treichler, \& Meyer, 1965). Our experiment is summarized in Figures 7 and 8 . The results indicate that each baboon was deceived by the Zöllner illusion in almost every case.

Coren and Girgus (1977) have suggested that most illusory distortions are the result of a number of different mechanisms at the level of eye and brain and are subject to alterations by psychological events of the past and the present. Illusions may also be explained in terms of mistaken perceptual impressions of depth cues that are implicit in spatial patterns (Gregory, 1973). It seems unlikely that for a nonhuman primate the Zöllner illusion "is due to misplaced assumptions" (Gregory, 1973) or that monkeys possess a predisposition that automatically assigns a representational status to arrays of twodimensional contours (Coren \& Girgus, 1977).

Deregowski $(1968,1973)$ has described the differences in the perception of pictures in various human cultural groups, particularly in the more primitive ones. All these reports appear to support the idea of a biological rather than an environmental aspect to visual illusions. The fact that the feral nonhuman primates used in this experiment arrived in Rehovot at the age of 18 months, spent over 5 years in the colony room before being tested, but were deceived by the Zöllner illusion does not support any theory based on experience or environmental factors.

\section{REFERENCE NOTE}

1. Benhar, E., \& Samuel, D. Discrimination of shape and colour in the baboon. Manuscript in preparation, 1982.

\section{REFERENCES}

Benhar, E., Carlton, P. L., \& Samuel, D. A search for mirrorimage reinforcement and self-recognition in the baboon. In S. Kondo, M. Kawai, \& A. Ehara (Eds.), Contemporary primatology. New York: Karger, 1975.

Benhar, E., \& Samuel, D. The establishment and maintenance of a small and inexpensive baboon colony for behavioral research. Journal of Medical Primatology, 1973, 2, 11-18.

Benhar, E., \& Samuel, D. A case of tool-use in the captive olive baboon. Primates, 1978, 19, 385-389.

Coren, S., \& Girgus, J. S. Illusions and constancies. In W. Epstein (Ed.), Stability and constancies of visual perception: Mechanisms and processes. New York: Wiley, 1977.

DeREGowsKi, J. B. Difficulties in pictorial depth perception in Africa. British Journal of Psychology, 1968, 59, 195-204. 
Denegowski, J. B. Illusion and culture. In R. L. Gregory \& E. H. Gombrich (Eds.), Illusion in nature and art. London: Duckworth, 1973.

DE VAlors, R. L. Primate color vision. Science, 1968, 162, 534-540.

Dominguez, K. A. A study of visual illusions in the monkey. Journal of Genetic Psychology, 1954, 85, 105-127.

Dücker, G. Untersuchungen ueber geometrisch-optische Taeuschungen bei Wirbeltieren. Zeitschrift für Tierpsychologie, 1966, 23, 452-496.

ERnst, A. J. R., \& Dericco, D. Effect of angle stimulation during development on adult discrimination ability in rats. Animal Learning \& Behavior, 1976, 4, 241-246.

Fellows, B. J. Chance stimulus sequences for discrimination tasks. Psychological Bulletin, 1967, 67, 87-92.

Gregory, R. L. Distortion of visual space as inappropriate constancy scaling. Nature, 1963, 199, 678-680.

Gregory, R. L. Visual illusions. In B. Foss (Ed.), New Horizons in psychology. Baltimore, Md: Penguin Books, 1966.

Gregony, R. L. The confounded eye. In R. L. Gregory \& E. H. Gombrich (Eds.), Illusion in nature and art. London: Duckworth, 1973.

Herter, K. Weitere Dressurversuche an Fischen. Zeitschrift für Vergleichende Physiologie, 1930, 11, 730-748.

Meyer, D. R., Treichlen, F. R., \& Meyer, P. M. Discretetrial training techniques and stimulus variables. In A. M. Schrier, H. F. Harlow, \& F. Stollnitz (Eds.), Behavior of nonhuman primates: Modern research trends (Vol. 1). New York: Academic Press, 1965.
Newman, C. V., \& Newman, B. M. The Ponzo illusion in pictures with and without suggested depth. American Journal of Psychology, 1974, 87, 511-516.

RoBinson, J. O. The psychology of visual illusions. London: Hutchinson University Library, 1972.

Sarmiento, R. F. The stereoacuity of macaque monkeys. Vision Research, 1975, 15, 493-498.

Tolansky, S. Optical illusions. London: Pergamon, 1964.

Ward, L. M., Porac, C., Coren, S., \& Girgus, J. S. The case for misapplied constancy scaling: Depth associations illicit by illusion configurations. American Journal of Psychology, 1977, 90, 609-620.

Worall, N. A test of Gregory's theory of primary constancy scaling. American Journal of Psychology, 1974, 87, 505-511.

Young, F. A., \& Farber, D. H. Visual similarities of nonhuman and human primates. In E. I. Goldsmith \& J. MoorJankowsky (Eds.), Medical primatology. Basel: Karger, 1970.

\section{NOTE}

1. A third baboon had to be dropped during the course of the experiment because he was found to have severe myopia in both eyes. Our thanks are due to Dr. M. Oliver, head of the Ophthalmology, Department of the Kaplan Hospital, Rehovot, for conducting the optometric examination.

(Manuscript received September 23, 1980; revision accepted for publication September 2, 1981.) 